\title{
Reflections on Centaur Upper Stage Integration by the NASA Lewis (Glenn) Research Center
}

\author{
Scott R. Graham* \\ NASA Glenn Research Center, Cleveland, Ohio 44135
}

\begin{abstract}
The NASA Glenn (then Lewis) Research Center (GRC) led several expendable launch vehicle (ELV) projects from 1963 to 1998 , most notably the Centaur upper stage. These major, comprehensive projects included system management, system development, integration (both payload and stage), and launch operations. The integration role that GRC pioneered was truly unique and highly successful. Its philosophy, scope, and content were not just invaluable to the missions and vehicles it supported, but also had significant Agencywide benefits. An overview of the NASA Lewis Research Center (now the NASA Glenn Research Center) philosophy on ELV integration is provided, focusing on Atlas/Centaur, Titan/Centaur, and Shuttle/Centaur vehicles and programs. The necessity of having a stable, highly technically competent in-house staff is discussed. Significant depth of technical penetration of contractor work is another critical component. Functioning as a cohesive team was more than a concept: GRC senior management, NASA Headquarters, contractors, payload users, and all staff worked together. The scope, content, and history of launch vehicle integration at GRC are broadly discussed. Payload integration is compared to stage development integration in terms of engineering and organization. Finally, the transition from buying launch vehicles to buying launch services is discussed, and thoughts on future possibilities of employing the successful GRC experience in integrating ELV systems like Centaur are explored.
\end{abstract}

\begin{tabular}{|c|c|c|}
\hline & & Nomenclature \\
\hline $\mathrm{AC}$ & $=$ & Atlas/Centaur \\
\hline ADDJUST & $=$ & Automatic Determination and Dissemination of Just Updated Steering Terms \\
\hline CISS & $=$ & Centaur Integrated Support System \\
\hline CRRES & $=$ & Combined Release and Radiation Effects Satellite \\
\hline ELV & $=$ & expendable launch vehicle \\
\hline EOS & $=$ & Earth Observing System \\
\hline ERB & $=$ & Engineering Review Board \\
\hline FLTSATCOM & $=$ & Fleet Satellite Communications \\
\hline GFE & $=$ & government-furnished equipment \\
\hline GOES & $=$ & Geosynchronous Operational Environmental Satellite \\
\hline GRC & $=$ & Glenn Research Center \\
\hline HQ & $=$ & Headquarters \\
\hline IUS & $=$ & inertial upper stage \\
\hline IV\&V & $=$ & independent verification and validation \\
\hline $\mathrm{JSC}$ & $=$ & Johnson Space Center \\
\hline $\mathrm{KSC}$ & $=$ & Kennedy Space Center \\
\hline LeRC & $=$ & Lewis Research Center \\
\hline $\mathrm{LH} 2$ & $=$ & liquid hydrogen \\
\hline LOX & $=$ & liquid oxygen \\
\hline $\mathrm{RF}$ & $=$ & radiofrequency \\
\hline RTG & $=$ & radioisotope thermoelectric generator \\
\hline $\mathrm{SC}$ & $=$ & Shuttle/Centaur \\
\hline SEP & $=$ & solar electric propulsion \\
\hline $\mathrm{SOHO}$ & $=$ & Solar and Heliospheric Observatory \\
\hline ULA & $=$ & United Launch Alliance \\
\hline
\end{tabular}

\footnotetext{
*Associate Director, Space Flight Systems, Mail Stop 3-6, 21000 Brookpark Road, Cleveland, Ohio 44135.
} 


\section{Introduction}

$\mathrm{T}$ THE NASA Glenn (then Lewis) Research Center (GRC) led and managed several expendable launch vehicle (ELV) projects from 1963 to 1998, most notably the Centaur upper stage. These major, comprehensive projects included system management, system development, integration (both payload and stage), and launch operations. The integration role that GRC pioneered was truly unique and highly successful. Its philosophy, scope, and content were not just invaluable to the mission and vehicles it supported, but also had significant Agency-wide benefits that might also be useful to future NASA activities.

NASA's Centaur upper stage was the first of a new generation of space vehicles that pioneered the use of liquid hydrogen as a fuel for space flight rocket engines. The Centaur upper stage was developed by NASA Lewis Research Center, now Glenn Research Center ${ }^{1}$ in Cleveland, Ohio. The Centaur became the world's first highenergy upper stage, burning liquid hydrogen (LH2) and liquid oxygen (LOX) to place payloads in geosynchronous orbits or provide escape velocity for interplanetary space probes. In combination with the RL10 rocket engine (currently manufactured by Aerojet Rocketdyne), the Centaur became (and still is today) the highest performing upper stage and one of the most prominent launch vehicles in America's exploration of space. Centaur has launched over 200 payloads, most notably the Surveyor landers to the Moon (a precursor to the Apollo lunar landings), the Pioneer and Voyager spacecraft to the outer planets, the Viking landers and the Curiosity rover to the surface of Mars, Cassini to the rings of Saturn, and the New Horizons probe to Pluto. Centaur has also launched dozens of communication satellites into geosynchronous orbit.

The Centaur upper stage was developed and manufactured by General Dynamics Convair Aerospace Division (later renamed to Space Systems Division) under the direction of NASA's LeRC. The Centaur Program started in 1958 with its first successful flight (AC-2) on November 27, 1963, from Cape Canaveral Air Force Station in Florida. Since then the vehicle has undergone numerous evolutionary upgrades and modifications to improve its performance, operability, and reliability. Centaur has flown as the upper stage for both the Atlas and Titan launch vehicles, and continues flying today as the upper stage for the Atlas V. Last year (November 2013) marked the $50^{\text {th }}$ anniversary of the first successful flight of Centaur. In the early 1980s, NASA embarked upon a large effort to modify Centaur to safely fly as a high-energy upper stage inside the space shuttle cargo bay for NASA missions such as Galileo and Ulysses, and certain Department of Defense missions. This program, known as Shuttle/Centaur, was cancelled in 1986 shortly after the Space Shuttle Challenger accident, just a few months prior to the planned first launch in May 1986. The Centaur G-prime upper stage developed for the Shuttle/Centaur program later flew as a new upper stage for Titan IV.

This paper will reflect on NASA GRC's unique and highly successful role in managing and integrating ELVs, with emphasis on the Centaur upper stage development and integration with Atlas, Titan, and the space shuttle.

\section{LeRC Philosophy on Centaur/ELV Integration}

LeRC's management philosophy for launch vehicle integration was centered on having a robust and highly competent in-house technical staff working in partnership with contractor personnel and the launch organizations. A true government-industry team was developed in which each organization supported, stimulated, and challenged the other to produce a whole that was greater than the sum of the parts. The government-industry team was highly experienced and dedicated to mission success, with considerable pride and confidence that served to maintain a high level of morale and motivation.

With its acknowledged technical leadership, LeRC evolved into a position of manager and system integrator of associate contractors, supplying the guidance subsystem and RL10 engines as government-furnished equipment (GFE) to General Dynamics Convair as the prime integrating contractor. This mode of operation was well conceived and highly successful for many years, up until LeRC's ELV program transitioned into procuring launch services from industry. Up until that transition, LeRC managed separate contracts with General Dynamics Convair (multiple contracts), Teledyne (Centaur digital computer), Honeywell (Centaur guidance), Pratt \& Whitney (Centaur RL10 engines), and Rocketdyne (Atlas MA-5 engines). These associate contractors delivered flight-qualified hardware to LeRC that was then furnished to General Dynamics in San Diego. Figure 1 shows the Centaur program organization in 1980 including the LeRC-managed contracts.

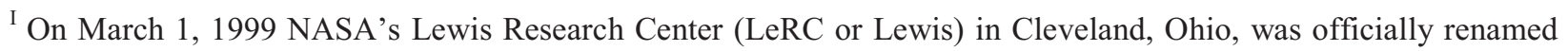
the John H. Glenn Research Center at Lewis Field ( GRC or Glenn). Because of the historical nature of this paper both center names, Lewis (LeRC) and Glenn (GRC), are used interchangeably herein.
} 
The experience, depth of technical penetration, and familiarity of the LeRC project staff with the Atlas/Centaur vehicle was a major strength of the program. This supplied both a "corporate memory" and person-to-person familiarity with their counterparts among the contractors. ${ }^{1}$ As an example of this technical penetration and government-industry partnership, LeRC assigned a highly competent engineer to be the system engineer for the RL10 rocket engine and worked on a day-to-day basis with his counterparts at Pratt \& Whitney and General Dynamics. This governmentindustry engineering counterpart arrangement was repeated for most every major system and subsystem (hydraulic, pneumatic, guidance, computer, avionic, structure, thermal, etc....). This not only provided a tightly coupled governmentindustry team, but also provided the government with significant technical penetration into all

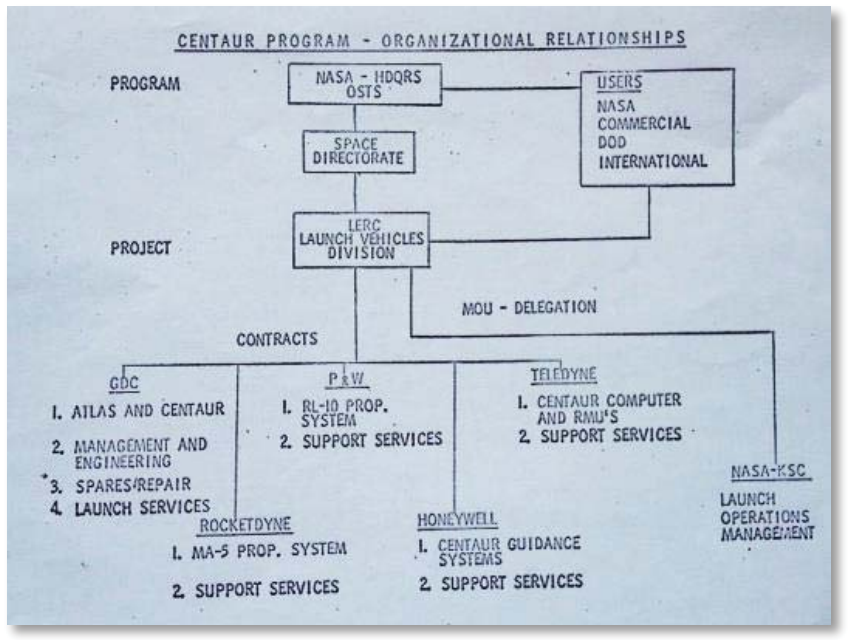

Figure 1. Centaur Program organization showing LeRCmanaged contracts (circa 1980). aspects of the designs and hardware. It also served as a check-and-balance system to assure mission success. Many times the LeRC system engineer was more knowledgeable about a particular issue, component, or design feature than his industry counterpart. Responsibilities of the GRC launch vehicle systems engineers, assigned as a technical specialist for a particular system or subsystem, included $^{2}$

- Mission integration interfaces

- Problem solving

- Evaluation and qualification testing

- Factory acceptance

- "Tiger Team" product reviews

- Flight readiness status

- Launch support

- Flight data reduction analysis

- Flight report

- Contract support

- Liaison with contractor and Kennedy Space Center (KSC) counterparts

Atlas/Centaur is an extremely complex vehicle with minimal redundancy, and flight success required an unusual degree of both care and familiarity on the part of all system and subsystem engineers. ${ }^{3}$ Flight failures were often not caused by gross design flaws but by things being forgotten or "slipping through the crack." 4

\footnotetext{
"The technical penetration by the Lewis project team was more than just monitoring and directing the contractors to ensure that they do a good job. When competence in government meets competence in industry, a synergism occurs: the whole is greater than the sum of the parts. Each party stimulates and challenges the other to a higher level of care and diligence than would otherwise be obtained. The success of Atlas/Centaur could not have been achieved by either government or industry alone."3
}

LeRC's philosophy for Centaur mission success was also built on a foundation of extensive ground testing in the relevant environment-from components, to subsystems, systems, to the complete vehicle. Types of testing conducted included engine hot fire tests, separation, vibration, structural, etc... LeRC's emphasis on ground testing, coupled with an experienced technical staff and unique test facilities were critical to the successful development and operation of the Centaur. ${ }^{5}$ Figure 2 shows a Centaur upper stage being lowered into position for testing at LeRC. 


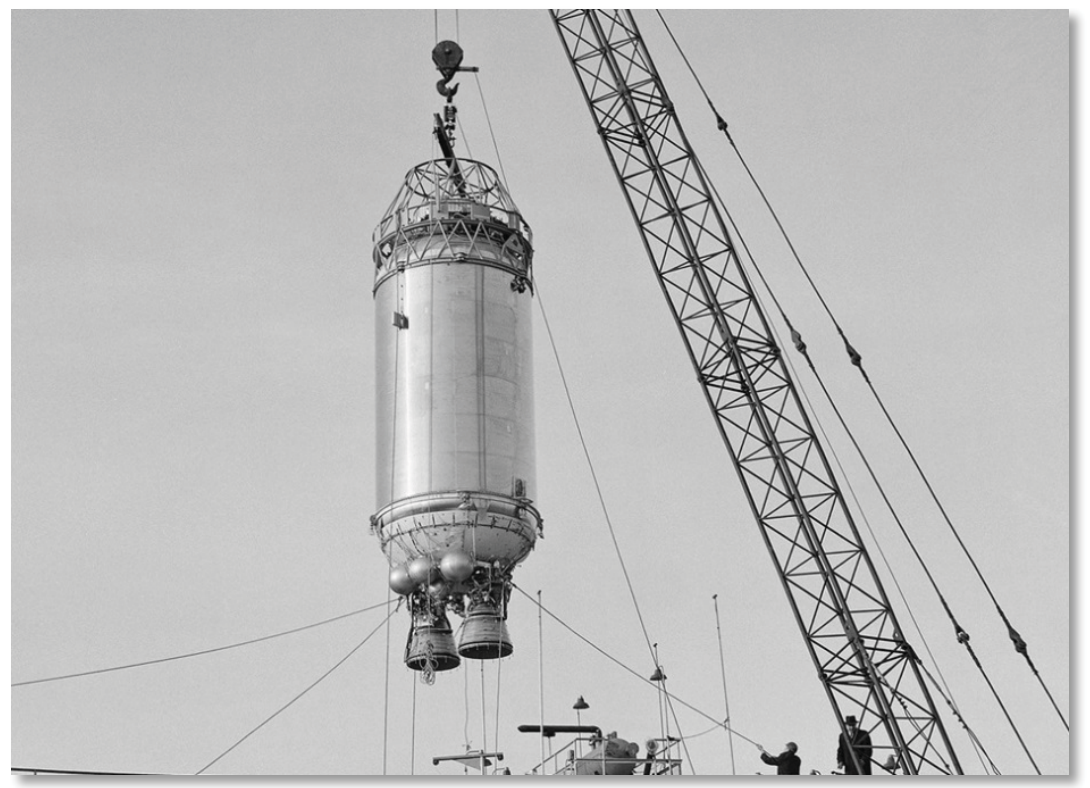

Figure 2. A Centaur stage being readied for testing.

As problems arose, LeRC's program philosophy was to maintain close contact with the contractor's engineering and quality personnel for awareness and resolution. Engineering Review Boards (ERBs) were often conducted by both the contractor and LeRC. Sometimes joint NASA-industry ERBs were conducted for particular problems. A very formal, well-documented process existed for conducting business and reviews. Both industry and LeRC management were kept well informed of current status, problems, and problem resolution activities. Senior management was tightly engaged with the systems engineering and quality assurance personnel, to ensure no surprises. The engineering and project management organizations at GRC were within the same Directorate, not matrixed. This "stove-

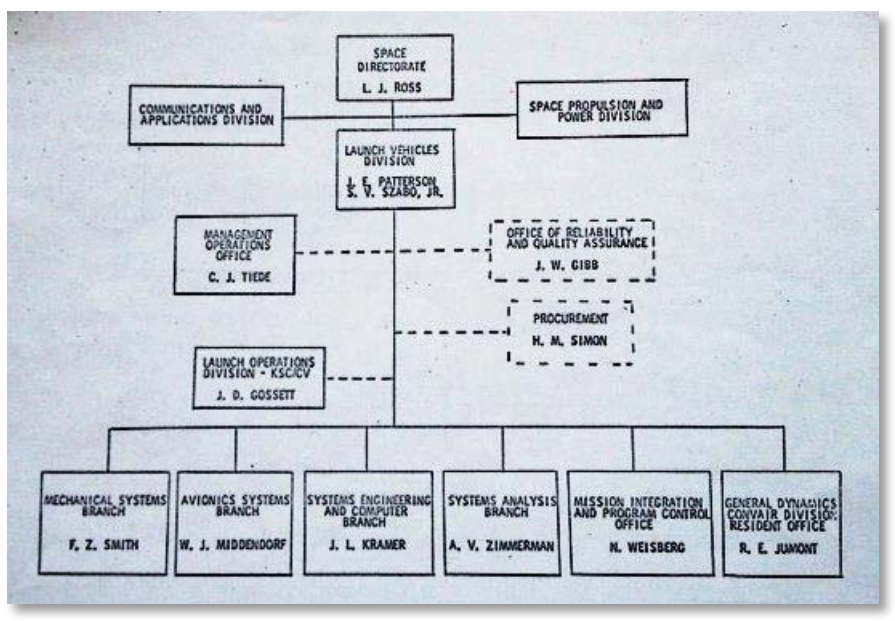

Figure 3. LeRC Launch Vehicles Division organization (circa 1980). piped" organization was effective in focusing experienced engineers on solving problems in a timely fashion. Figure 3 shows the LeRC Launch Vehicles Division organization in 1980. Lower level organization "sections" are not shown. Launch vehicle staffing levels at GRC fluctuated around 100 to 150 people for the majority of the years. (There was a ramp up to near 250 people in the early 1980s for Shuttle/Centaur development.) In the early 1980s, GRC began augmenting its civil servant staff with on-site engineering support contractors. Throughout GRC's leadership of launch vehicles and Centaur, the Center maintained and staffed a resident office at General Dynamics in San Diego and later at Lockheed Martin in Denver. GRC also maintained an on-site presence at other associate contractor locations. Likewise, the major contractors maintained a local representative in Cleveland, near GRC. GRC staff also cochaired technical working groups and panels in key areas along with their contractor counterparts. GRC staff sometimes shared operational work responsibilities with contractor staff during critical launch preparation periods. Functioning as a cohesive team was more than a concept - where GRC upper management, NASA Headquarters (HQ), contractors, payload users, and all staff worked together as a team, not as government versus contractor. 
LeRC's approach to launch vehicle integration and mission success rejected the approach of contracting out all technical and engineering matters to industry. LeRC's approach was much more than simply providing contract management, oversight, and insight. LeRC's deep technical penetration into all aspects of the vehicle, an engineering staff comparable to the contractor's staff, and working in close partnership and collaboration with industry, helped ensure a highly successful program for many decades. Attention to detail was paramount. The LeRC team brought hands-on experience coupled with equal-to or superior analytic tools and testing facilities compared with the contractors. LeRC's trajectory optimization, mission design, and coupled loads analysis tools are but a few examples of LeRC's superior tools. The Center's large-scale vacuum chambers for hot fire engine and stage testing (at altitude conditions) of Centaur during its early development were crucial to the success of the program.

GRC's philosophy for Centaur flight software was to design and structure it to be very flexible and "robust." It could compensate for very large in-flight dispersions or even for some hardware anomalies. For example, it could initiate main engine restart sequences, recover from very high tumble rates after Centaur engine shutdown, and retarget in flight. The software was able to respond to many hardware dispersions or anomalies. Three examples of this philosophy are briefly explained here. First, if a Centaur main engine failed to start, software initiated a main engine restart sequence. This software capability was actually invoked on the first Titan/Centaur flight, a test flight where the Centaur engines failed to start after separation from Titan. The software initiated an engine restart sequence, but the engines still failed to start for hardware reasons. Second, in the event of very high Centaur/payload tumble rates after Centaur engine shutdown (i.e., during coasting) special software initiated commands to recover control of the vehicle, even if it meant that the vehicle rotated through $360^{\circ}$ before control was regained. It had been shown analytically that this approach was preferable to running out of attitude control propellant trying to null the high rate quickly and then returning to the proper attitude. And finally, if on-board guidance and navigation calculations indicated that the desired target was unreachable because of some anomaly earlier in flight, a new target would actually be computed in flight using an onboard algorithm. This retarget would result in a compromised mission, (e.g., a lower orbital altitude), but such a mission was preferable to losing the spacecraft by running out of propellant before reaching orbit trying to achieve the original nominal target.

\section{Scope and Content of Integration}

As the NASA lead Center for management of intermediate- and large-class ELVs (such as Atlas/Centaur and Titan/Centaur), GRC was responsible for ensuring that the total launch vehicle and mission integration tasks and activities were properly coordinated and conducted in support of the mission. ${ }^{6}$ These integration tasks and activities included the following:

- Integrated launch vehicle performance and trajectory analyses

- Integrated launch vehicle loads analyses

- Integrated launch vehicle thermal analyses

- Integrated guidance accuracy analyses

- Launch vehicle guidance and flight control integration

- Integrated launch vehicle radiofrequency (RF) analyses

- Integrated launch vehicle range and pad safety analyses, including flight termination

- Integrated launch vehicle range planning and data acquisition

- Integrated launch vehicle operations support

- Overall launch vehicle schedule integration

- Launch vehicle systems trade studies

A standardized integration panel structure was utilized for each mission. For most missions there were three panels: Mission Integration, Mission Design, and Ground Operations. For planetary or deep-space missions, a radioisotope thermoelectric generator (RTG) panel was frequently required. All the panels were cochaired by GRC launch vehicle personnel. The ground operations panel was cochaired by KSC and GRC. Each panel had welldocumented responsibilities. These panels were sometimes referred to as working groups. As shown in Figure 4, these panels were typically established about 3 years prior to launch (L-3 Years) for each mission. 


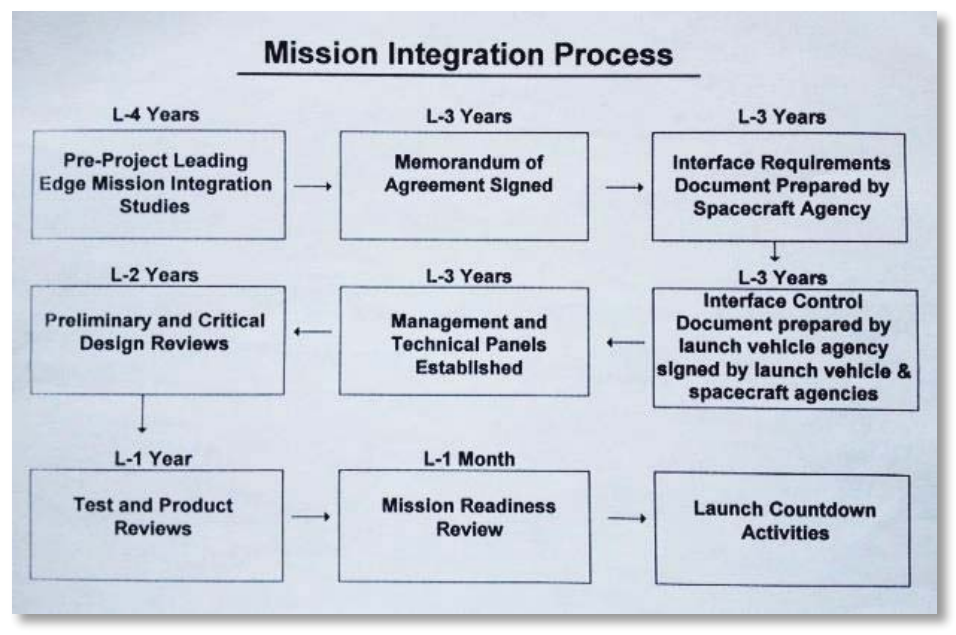

Figure 4. Typical mission integration process (circa 1996).

The Mission Integration Panel, sometimes referred to as the Systems Integration Panel, was responsible for the overall management of the integration process, which included the following:

- Systems safety

- Systems effectiveness

- Scheduling and planning

- Action item review and status

- Initiation/formation of working groups

- Resolution of integration disagreements

- Mechanical, electrical, and environmental interface requirements definition (flight and ground)

Mission Integration Panel products included

- Integration schedules

- Safety documentation

- Interface control documents and drawings, electrical and mechanical

- Postflight reports

- Flight certification assessment

The Mission Design Panel was responsible for all aspects of mission design and operations between the launch vehicle and the payload/spacecraft, including

- Assuring that all phases of mission design were consistent with performance, trajectory, guidance, and launch period requirements of the mission

- Providing a means for continual compilation, interchange, review, and evaluation of relative data

- Interpreting performance and guidance accuracy requirements and verifying that they were satisfied

- Developing appropriate trajectory strategies to meet tracking and data acquisition constraints

- Verifying nominal and contingency trajectory timelines and flight profiles

- Supporting and providing inputs to interface control documents and other documents

- Coordinating performance improvement studies and analyses

- Developing and issuing performance tracking reports

- Identifying and analyzing problems and determining possible courses of action and recommended solutions 
The Ground Operation Panel was responsible for defining facility interfaces and services as well as defining and integrating ground operations including payload encapsulation and scheduling of launch operations from the time the launch vehicle and payload arrived at KSC through launch. Additional responsibilities included

- Coordinating the preparation of all ground operation procedures

- Verifying that all spacecraft ground support equipment is provided with proper services

- Coordinating the preparation and approval of various spacecraft and launch vehicle program requirement documents

- Reviewing and updating launch site schedules

- Coordinating and communicating requirements among payload, launch vehicle, and NASA organizations

- Coordinating launch site badging and security

- Coordinating tracking and data acquisition requirements and services

- Monitoring range safety activities leading up to range approval of mission flight plans

For planetary or deep-space missions, the RTG panel was responsible for compiling and publishing a RTG safety data book in support of the environmental impact statement and safety analysis report. This included definition of launch vehicle accident scenarios, the resulting vehicle response, probability of occurrence, definition of environments resulting from accident scenarios, and identification of accident mitigation techniques to reduce the severity of accident environments.

\section{Payload Integration Versus Stage Development Integration}

There were two different aspects of launch vehicle integration at GRC: payload/spacecraft integration and vehicle development integration. GRC managed over 119 launches and integrated 80 different payloads or spacecraft with the Centaur upper stage. Beyond early development test flights, every launch vehicle (Atlas/Centaur and Titan/Centaur) managed by GRC had a payload or spacecraft that was integrated with the launch vehicle by GRC personnel working in collaboration with the payload provider and the launch vehicle contractor. Payloads included commercial spacecraft, such as the Intelsat series of communication satellites, military satellites such as Fleet Satellite Communications (FLTSATCOM) for the Department of Defense, and many NASA planetary and solar system spacecraft, such as the Surveyor and Mariner series, Pioneer, Viking, Voyager, Cassini, and the Solar and Heliospheric Observatory (SOHO). Figure 5 shows the launch of Surveyor 1 on AC-10 in May 1966.

The nature of payload integration was very analytical and closely coupled with the mission design, vehicle performance, and the trajectory. Payload integration included making sure the spacecraft physically fit and interfaced properly with the launch vehicle and launch site ground support equipment and that the spacecraft would survive the environments induced by the launch

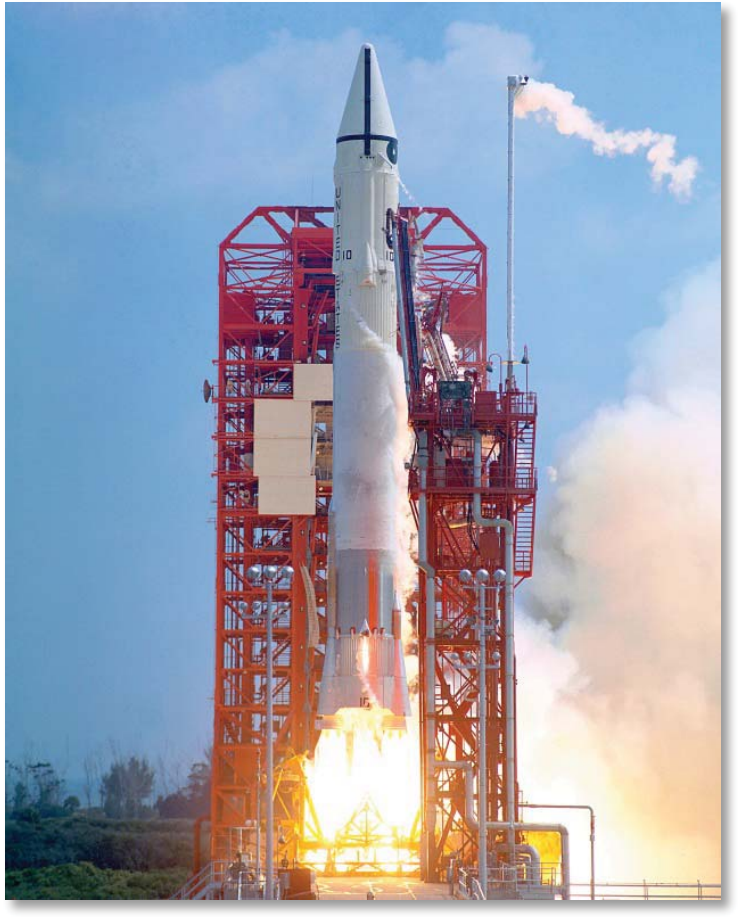

Figure 5. Surveyor 1 launch on AC-10 (May 1966). vehicle during launch, such as temperatures, pressures, gforces, loads, vibration, and acoustic noise levels. Payload integration also included making sure the payload requirements for services from the launch vehicle or the launch pad were understood and provided. Typical payload services included providing access to the payload (if required) after it was encapsulated inside the payload fairing; environmental control (thermal conditioning, purge gas); prelaunch electrical power, data, and command; and other services provided to the spacecraft via umbilical connections from the launch pad tower to the payload. GRC payload integrators and mission integration managers were intimately familiar with the spacecraft requirements, 
interfaces, and environmental design limits and worked to ensure the launch vehicle environments were compatible with the environments the spacecraft was designed to withstand, with adequate margin.

In contrast to the 80 payloads that were integrated by GRC, integration of launch vehicle stages happened infrequently. For Centaur, there were only four substantially different versions developed for launch on three booster families over a 35-year period. These different Centaur configurations are commonly referred to as the Atlas/Centaur configuration, the Titan IIIE/Centaur configuration, and two Shuttle/Centaur configurations - the Centaur G and Centaur G-prime configurations.

A new Centaur configuration was a major undertaking that involved all the contractors and NASA. It was during these vehicle redesign efforts that the value and benefit of the joint industry-GRC partnership and collaboration really shined, as it did from the very beginning during the initial design and development of the Centaur upper stage.

Centaur was born out of the necessity to have a high-performance upper stage for the Atlas booster to launch the Surveyor robotic landers to the Moon as a precursor to the Apollo human landing missions. Centaur was the world's first high-energy upper stage - the first to use LH2 and LOX as propellants, leveraging the remarkable and legendary RL10 rocket engine as its propulsion system and ultra-lightweight, very thin, pressure stabilized, stainless steel propellant tanks; that were separated by a common bulkhead. Atlas was originally developed by the United States Air Force as an intercontinental ballistic missile. Derivatives of Atlas were later used by the Air Force and then NASA for launching payloads (and eventually humans) into space. The Atlas booster used a refined kerosene RP-1 fuel and liquid oxygen as its oxidizer. NASA used Atlas as a booster for its Agena upper stage and for the Mercury-Atlas human missions (after the two Mercury Redstone launches of Alan Shepard and Virgil "Gus" Grissom). Atlas was used to launch John Glenn and the Friendship 7 Mercury capsule on his historic journey in February 1962. Three more Mercury-Atlas missions followed. GRC pioneered the use of LH2 as a high-energy propellant and led the development of the RL10 rocket engine with Pratt \& Whitney and the Centaur upper stage with General Dynamics Convair. Atlas became the first booster for Centaur, and GRC led the integration of Centaur onto Atlas. The first successful Atlas/Centaur launch (AC-2) was in November 1963. Last year, in November 2013, many members of the GRC Centaur team gathered in Cleveland with their industry and payload partners and NASA senior managers to celebrate the $50^{\text {th }}$ anniversary of the first successful Atlas/Centaur launch. Atlas and Centaur continue to fly today as the Atlas V ELV. It is not the scope of this paper to reflect in any more detail on the early development history of Atlas, Centaur, and the RL10 rocket engine. Those efforts are well described in the Taming Liquid Hydrogen historical book. ${ }^{7}$

Examples of GRC's contributions to the Atlas/Centaur integrated vehicle configuration included performing structural dynamic tests of the full-scale Atlas/Centaur with a dynamic Surveyor spacecraft model at LeRC's E Stand at Plum Brook Station in the 1960s. These tests verified the dynamic models for loads, pogo, and autopilot stability analysis. Also in the 1960s GRC developed the Atlas vehicle ground wind damper and the linear-shaped charge for the separation system that separated Centaur from Atlas. GRC was also instrumental in the development of a new Atlas/Centaur nose fairing and fairing jettison system, which were tested at LeRC's Space Power Facility at Plum Brook, the world's largest vacuum chamber. In the 1970s GRC led the development of a computercontrolled Centaur tank pressurization and vent system as well as the computer-controlled launch set (CCLS), the ground-based computer system used to monitor, calibrate, test, and display system status and redlines prior to launch. Another significant GRC accomplishment was the development, in close collaboration with General Dynamics, of a new launch-day wind-monitoring and vehicle-steering system in 1973 known as Automatic Determination and Dissemination of Just Updated Steering Terms (ADDJUST). The premise of ADDJUST was to use high-altitude wind data from weather balloons launched just prior to launch to provide up-to-date vehicle guidance and steering (pitch and yaw) parameters to the Centaur flight control computer 15-minutes before launch to steer the vehicle through the winds to minimize loads on the vehicle during ascent. The ADDJUST system dramatically reduced the number of launch scrubs due to upper-atmosphere winds and increased the number of days available for launch — especially during the winter season of high-upper-atmosphere winds in Florida.

The Titan IIIE/Centaur D-1T configuration, developed in the early 1970s, had triple the payload capability of Atlas/Centaur. The development of Titan/Centaur was driven by the need to launch the heavy Viking landers to Mars in 1975. After its maiden test flight in February 1974 (which ended in failure when the Centaur RL10 engines failed to start), Titan IIIE/Centaur flew successfully six times, launching Viking 1 and 2, Voyager 1 and 2, and Helios 1 and 2. The last Titan IIIE/Centaur launch was Voyager 1 in September 1977. II Integrating Centaur with Titan proved to be a significant technical challenge. It required integrating together two vehicles, each with their own major aerospace company-General Dynamic's Centaur with Martin Marietta's Titan. Further complicating matters was the Air Force's ownership and control of Titan IIIE and the Complex 41 launch pad and other Titan

${ }^{\text {II }}$ Voyager 2 was launched 16 days before Voyager 1. 
facilities at Cape Canaveral. GRC stepped up to lead the integration of Titan/Centaur, working in partnership with General Dynamics, Martin Marietta, KSC, and the Air Force. Figure 6 shows the launch of Voyager 2 in 1977.

GRC's contributions to integrating Centaur with Titan IIIE included

- Leading the integration efforts with the aerospace contractors, KSC and the Air Force

- Development of the Titan Stage 1 oxidizer pogo suppression accumulator system

- Integrating the ADDJUST system into Titan/Centaur. (All seven Titan IIIE/Centaur launches used ADDJUST.)

- Development of a new payload shroud (Centaur Standard Shroud) for Titan/Centaur, including performing shroud jettison tests, including thermal vacuum tests, at Plum Brook

- Development of the Centaur guidance system to guide, steer, and control Titan, using the Centaur digital computer and avionics systems

- Development of a Centaur thermal radiation shield to enable in-space coasts for much longer periods (up to $5 \mathrm{~h}$ ) than Atlas/Centaur. (Although developed and demonstrated on Helios, this capability was never needed or used for a mission.)

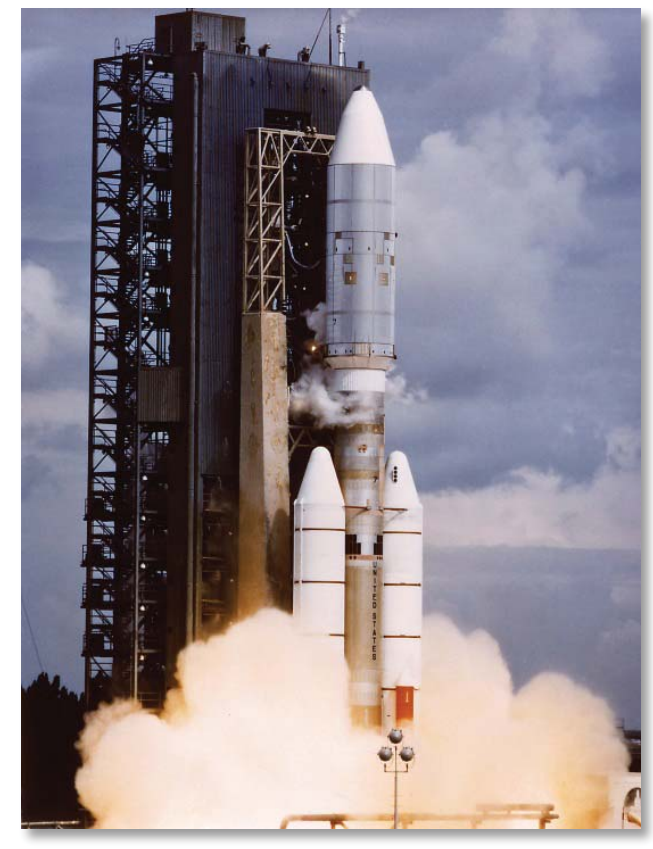

Figure 6. Titan IIIE/Centaur launch of Voyager 2 (1977).

Another challenge in integrating Centuar with Titan IIIE was the lack of clear and effective technical communication between the two major aerospace companies involved. The LeRC integration manager directed that a common database and set of definitions be established, documented, and maintained as the governing interface control drawings for the integration activity. This was no minor task because the two companies had differing cultures and design processes. ${ }^{8}$ In addition he directed that a complete structural and structural-dynamics analyses be conducted for the combined vehicle. This effort underscored the nature of the integration problems because the two companies did not use a common set of definitions for such analyses. The different cultures of Atlas and Titan programs proved a challenge for LeRC project managers. Air Force personnel were rotated every few years, a practice that prevented them from forming close personal relationships with their counterparts at Martin Marietta. In contrast, years of working together had produced a seamless relationship between LeRC and General Dynamics people. $^{9}$

The final major new Centaur configuration led and integrated by GRC was Shuttle/Centaur. In the early 1980s, NASA embarked upon a large effort to modify Centaur to fly safely as a high-energy upper stage inside the space shuttle cargo bay for NASA missions such as Galileo and Ulysses as well as certain Department of Defense missions. It is important to note that Shuttle/Centaur was very political in nature and that it began at around the time of the first space shuttle launch in 1981. At the beginning, Shuttle/Centaur was a political "hot potato" with the Agency cancelling it only to have Congress reinstate it. To better understand this, it is important to understand the environment of the late 1970s and early 1980s - the dawn of the space shuttle era and a tumultuous time for ELVs and Centaur.

With the development of the space shuttle, which began in 1972, it became NASA's official policy to terminate the use of all ELVs as soon as the space shuttle became available. As a result, for several years before the first space shuttle flight in 1981, the Atlas/Centaur program and the GRC-industry team was living and operating in a phase-out environment - an environment of near-term termination. In 1979 it appeared that AC-60, scheduled to launch in 1981, would be the very last Atlas/Centaur launch and the final Centaur mission. Around that time, the launch vehicle staff at GRC was reduced and planning was initiated to carry out the remaining launches in an orderly fashion and begin to phase-out all other engineering and sustaining activities. ${ }^{10}$ However in 1980, concern with space shuttle delays resulted in Intelsat requesting four more Atlas/Centaur launches that promised to extend the life of Atlas/Centaur for at least 4 years. The program continued along with no long-range prospects and only being able to manage one or two missions at a time as they came to be. An attitude that NASA would allow the possible coexistence of ELVs with the space 
shuttle started to emerge with a recommendation by the Atlas/Centaur Review Board in February 1981 that this become NASA policy. ${ }^{11}$ During this same time period, the Europeans entered the ELV market with their brand new Ariane launch vehicle. Ariane soon became a viable and competitive launch vehicle in the international market, creating additional pressures on the United States launch vehicle industry to remain competitive in a market they once dominated. This was the beginning of a shift towards recognizing the need for a robust, competitive, commercial space transportation industry, and the move towards commercializing ELVs in the United States began. This also marked the beginning of a shift within NASA from managing and buying ELVs (like Delta and Atlas/Centaur) to procuring launch services from industry. It would take several more years for this transition to occur, and GRC was at the forefront of making it happen. This transition from launch vehicles to launch services will be discussed in Section $\mathrm{V}$ of this paper.

During this same time period (early 1981), as the space shuttle began to fly, it became apparent that the space shuttle needed a capability to launch payloads beyond low Earth orbit. The idea to redesign Centaur to fit inside the space shuttle was a radical idea that had been considered and studied in the 1970s, with a large integration study authorized by NASA HQ in 1979. The Shuttle/Centaur Program began in 1981 (albeit with low funding and an "onagain/off-again" first couple of years) and was hailed as the "convergence of piloted and robotic spacecraft and the next step in launch vehicle evolution. In an era of cost cutting and declining space budgets, the combination of the shuttle with the world's most powerful upper stage promised to give the United States a system of extraordinary power and versatility." ${ }^{\prime 2}$ There was also at the time a competing upper stage concept for the shuttle, the Air Force's solid propellant inertial upper stage (IUS) built by Boeing. A bitter political debate ensued between IUS camps (including Marshall Space Flight Center and its powerful delegation) and Centaur camps.

Unfortunately, Shuttle/Centaur was fraught with controversy and Agency and inter-center politics. The Johnson Space Center (JSC) wanted Centaur to be managed as shuttle payload, as opposed to an element of the Space Transportation System. The mass of a fully tanked Centaur with its payload stretched the abort landing capabilities of the shuttle orbiter. This necessitated designing a complex propellant dump system to quickly dump the liquid hydrogen and liquid oxygen from the Centaur in the event of an emergency abort landing to reduce mass. There were numerous safety concerns associated with flying hydrogen and oxygen inside the cargo bay of the shuttle in close proximity to the crew and their only ride home - especially with these propellants stored inside the Centaur's balloon-like pressure-stabilized tanks. In spite of those safety concerns, all the required safety precautions were addressed and all necessary emergency systems and redundancy plans were in place. In January 1986, Shuttle/Centaur SC-1 and SC-2 were only 4 months from launch (scheduled to launch 6 days apart in May 1986) and ready to be installed inside the Space Shuttle Challenger cargo bay for the Ulysses mission (SC-1) to the Sun and Space Shuttle Atlantis for the Galileo mission (SC-2) to Jupiter. However on January 28, 1986, the Space Shuttle Challenger tragically and catastrophically failed during launch and everything changed. The Agency became very risk adverse. The shuttle program was shut down for almost 3 years. The Shuttle/Centaur program was not officially terminated until June 19,1986, but its uncertainty and fate were largely known soon after the Challenger accident. Figure 7 shows artist concepts of Centaur G-prime being deployed from the Shuttle cargo bay with the Galileo spacecraft payload.
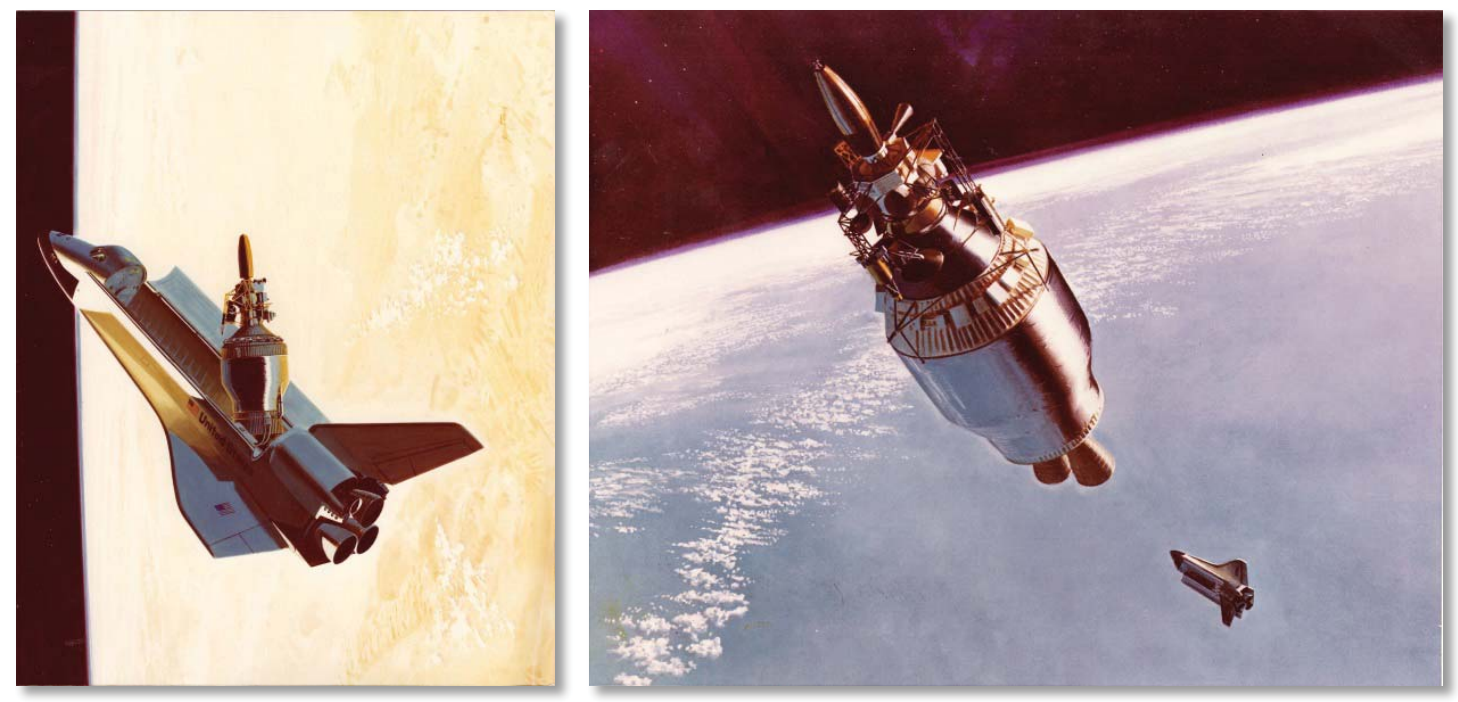

Figure 7. Artist concept of Shuttle/Centaur (with Galileo spacecraft) deployment from shuttle. 
GRC comanaged the development of Shuttle/Centaur with the Air Force. Although there was low-level, "onagain, off-again" activity and funding in 1981 and 1982, the program did not have significant funding and stability until 1983-only 3 years before the firmly scheduled first launch in May 1986. Meeting this schedule was critical for the program. The Galileo mission to Jupiter had to be launched within a 21-day window that month, or be delayed for over a year. GRC created the Shuttle/Centaur Project Office and hired additional staff. Launch vehicle staffing at GRC doubled to around 250 people in the mid-1980s during the peak of Shuttle/Centaur development. The Air Force maintained an on-site staff at GRC and was an integral, vital part of the Shuttle/Centaur Project Office. Together GRC and the Air Force comanaged the program including the integration of Centaur design and configuration changes to adapt the vehicle for the space shuttle platform and to ensure that Centaur addressed all human space flight requirements.

There were two versions or configurations of Centaur developed for the shuttle: Centaur G and Centaur G-prime. The G-prime version was $30 \mathrm{ft}$ long to accommodate 30 - $\mathrm{ft}$ long payloads. The $\mathrm{G}$ version was $20 \mathrm{ft}$ long and could accommodate payloads up to $40 \mathrm{ft}$ long. This was a result of different requirements for NASA missions versus Air Force missions. NASA's requirements were for a larger upper stage with the energy to achieve interplanetary velocity requirements. The Air Force requirements were for larger/longer payloads (40 ft) for Earth orbital missions. Both versions of Centaur were cradled inside the shuttle cargo bay in a device known as the Centaur Integrated Support System (CISS). The CISS was a major new systems development activity for the program. The CISS provided all of the mechanical, electrical, and fluid interfaces between the Centaur and the shuttle. The CISS not only supported the Centaur during space shuttle flights, it also provided the means to control and deploy the Centaur. With the cargo bay doors open, the CISS would rotate (pivot) the Centaur up and out of the cargo bay and then release it. The CISS was designed to be reusable and returned to Earth inside the shuttle cargo bay. Both versions of Centaur with the payload/spacecraft and the CISS filled the entire cargo bay of the space shuttle. The two space shuttle orbiters designated to carry Centaur, Challenger and Atlantis, also had to be modified for Centaur. These modifications included provisions for filling and draining the Centaur propellant tanks, venting the tanks, and dumping the tanks in the event of an abort landing. Figure 8 shows the first Centaur G-prime vehicle being processed for launch at KSC. The CISS can be seen in the photograph on the right, at the bottom.
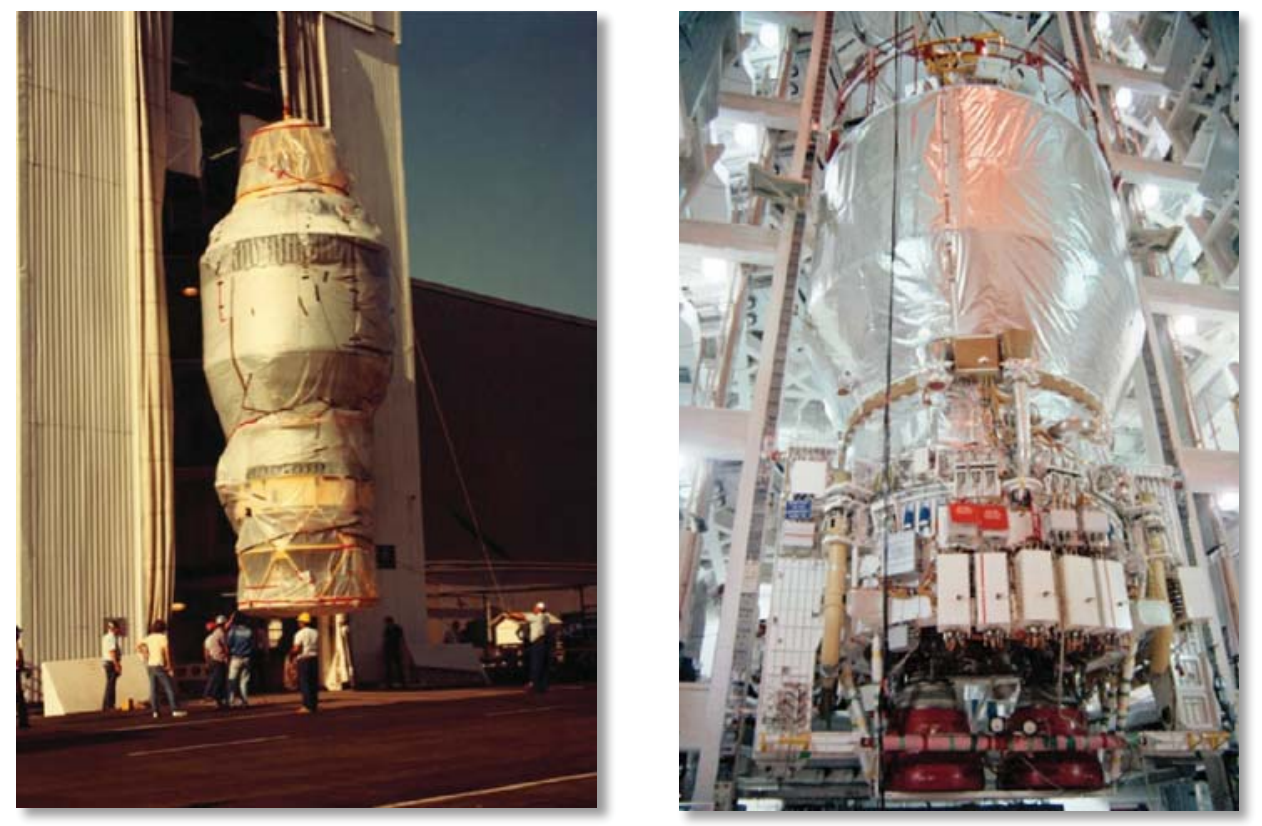

Figure 8. Shuttle/Centaur G-prime processing at Kennedy Space Center (CISS also shown at right).

There were many design changes and modifications required for Centaur $G$ and G-prime. The launch environment of the space shuttle was totally different than that of Atlas and Titan. Significant human rating requirements had to be addressed. The RL10 rocket engine had to be able to transition to the new Centaur design and shuttle environments with minimal changes. This included accommodating space shuttle environments, operating constraints, launch loads, different propellant mixture ratios, prelaunch cooling replaced with multirevolution/on-orbit chill-down, and accommodating new Centaur interfaces for the propulsion system. 
Other Centaur design changes included

- New propellant tank diameters and lengths

- New conical transition to the LH2 tank

- New propellant fill, drain, and dump system

- New separation disconnects to separate the Centaur from the CISS and the shuttle

- New aft adapter and separation ring

- New forward adapter

- New S-band transmitter and RF system compatible with the Tracking and Data Relay Satellite System

- Added system and component redundancies

- New propellant isolation prevalves

- Ability to handle multiday on-orbit operations

From a vehicle design and integration standpoint, these technical design changes and interfaces were minor compared to the multitude of organizational interfaces. The organizational interfaces for Shuttle/Centaur included mission management, the Air Force, payload customers, NASA HQ, JSC, KSC, and finally the industrial contractors. The complexity of all these organizational interfaces was further compounded because most of these interfaces were "authoritative," meaning they had the power to influence or stop the progress of the overall mission. ${ }^{13}$ Relationships and interfaces with JSC were particularly challenging. Part of the problem was that GRC was given leadership responsibility of a key element of the Space Transportation System, rather than MSFC. GRC was an outsider in the NASA world of human spaceflight. Another issue, as mentioned earlier, was that Centaur ultimately was managed as, and treated by JSC as, a shuttle payload, rather than an element of the shuttle program. Centaur had to be designed to meet the requirements and criteria of a shuttle payload, which were vastly different than an element.

At the time the Shuttle/Centaur program was canceled in 1986 approximately a billion dollars had been spent, and two sets of flight articles (Centaur G-prime and CISS for SC-1 and SC-2), two G vehicles (approximately 50\% complete), and one ground-test article were produced. The space shuttle did not return to flight until September 1988. The Galileo mission to Jupiter was eventually launched in October 1989 using the less powerful IUS inside Space Shuttle Atlantis. The European Ulysses spacecraft was not launched until October 1990, also using the IUS, from Space Shuttle Discovery. A modified version of the Centaur G-prime ended up flying 16 times from 1994 to 2003 as the upper stage on the Air Force's Titan IV. This marked the return of Titan/Centaur, 17 years after the Voyager launches. Ironically, NASA decided to launch the Cassini mission to Saturn on a Titan IV/Centaur G-prime in 1997. The Cassini spacecraft was the last ELV payload integrated, managed, and launched by GRC.

During the four main years of the Shuttle/Centaur program (1983 to 1986), GRC continued to manage and launch Atlas/Centaur. The Shuttle/Centaur Project Office existed in parallel with the Atlas/Centaur Project Office. Both project offices received launch vehicle engineering support from the Space Transportation Engineering Division, led by Steve Szabo. The two project offices and the engineering division were all within the Space Directorate at GRC. Total launch vehicle staffing at GRC during this period reached nearly 250 people.

Separate from the major Centaur stage configuration changes (Atlas, Titan, Shuttle), GRC also co-led with industry other aspects of Centaur stage development and subsequent changes to the Centaur stage to improve performance and operability. In the 1960s, GRC led and performed structural tests for the Centaur equipment module, performed zero-gravity drop tower tests to better understand propellant behavior in low gravity, and developed a capacitance probe propellant utilization system to measure the propellant in the Centaur tanks. GRC engineers also developed a balanced thrust vent system to enable venting of the propellant tanks during in-space coast phases. In the 1970s, GRC was instrumental in the development of the Teledyne flight computer and flight software, the Honeywell guidance system, and a digital autopilot. In the 1980s, GRC led the elimination of the jettisonable insulation panels on the Centaur liquid hydrogen tank. The panels were replaced with fixed foam insulation. Also in the 1980s specifically for the AC-62 "stretched" Atlas G configuration (1984), GRC both eliminated the hydrogen-peroxide-powered boost pumps that increased propellant inlet pressures for the RL10 engines and performed numerous RL10 engine performance improvements, including engine thrust and specific impulse increases. For example, a silver throat insert was added to the RL10 engine to increase expansion ratio and specific impulse. GRC also led the development of a new hydrazine-based reaction control system for AC-62. The previous system used hydrogen peroxide. Unfortunately, with all these changes to Atlas and Centaur in 1984, the AC-62 launch was a failure due to a Centaur oxygen leak in the intermediate bulkhead that was believed to have

12

American Institute of Aeronautics and Astronautics 
occurred during Centaur's separation from Atlas. Figure 9 shows the AC-62 vehicle during a prelaunch test at Launch Complex 36B at Cape Canaveral Air Force Station.

GRC's launch vehicle development efforts and accomplishments were not limited to the Centaur stage. The same roles, responsibilities, expertise, and philosophy that GRC brought to Centaur applied equally to the Atlas booster and its MA-5 propulsion system. GRC personnel had the same relationship and partnership with the industry contractors for Atlas (General Dynamics) and MA-5 (Rocketdyne), as they did with Centaur. Some of the Atlas launch vehicle developments and configuration changes that GRC led included

- Structural strength testing at GRC's Plum Brook E-stand of a full-scale Atlas D tank to demonstrate buckling strength capability and bending strength (in the 1960s)

- Development of the SLV-3C Atlas with stretched propellant tanks (in 1966)

- Development of the stretched Atlas G for AC-62 (in 1984). Atlas $G$ was 81 inches longer than the previous Atlas configuration

- Development of the Atlas H configuration for DoD launches from Vandenberg Air Force Base

- Development of numerous Atlas MA-5 propulsion system upgrades (1963 to 1989), including booster

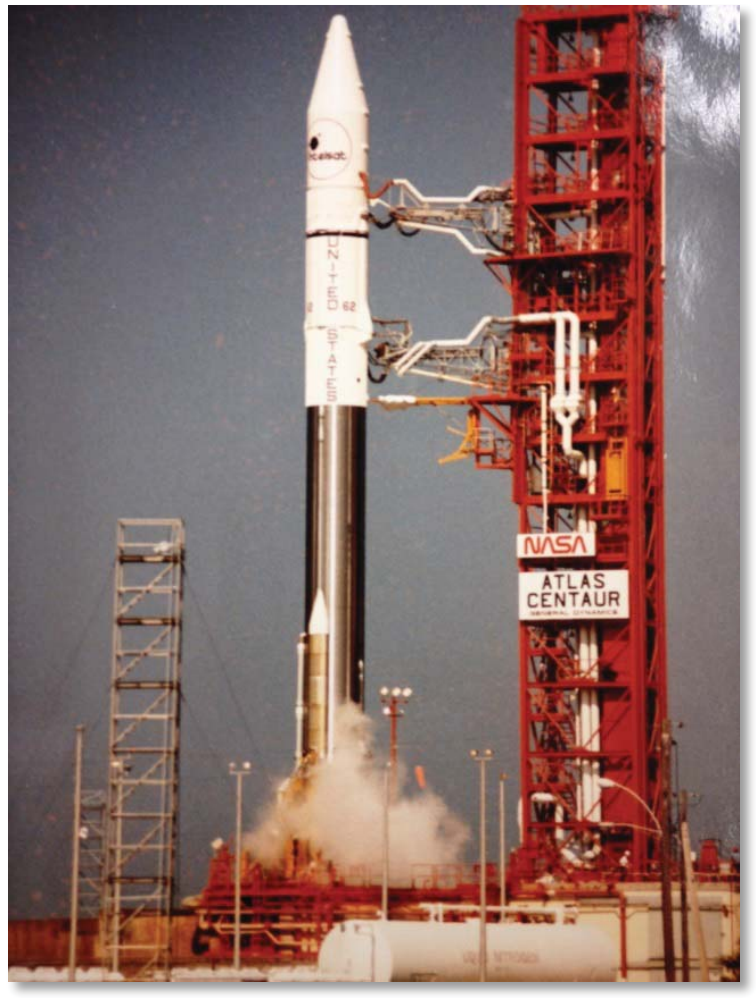

Figure 9. AC-62 during prelaunch test at Launch Complex 36B (photographed by the author). and sustainer engine thrust increase, elimination of the vernier roll-control engines, and a computerized Atlas propellant loading system

\section{Other LeRC ELV Leadership Accomplishments}

The Challenger accident in 1986 changed everything. NASA realized putting all its eggs into the space shuttle basket was a mistake; the country became too dependent on the space shuttle at a time when foreign countries (i.e., Europe's Ariane) were taking over the ELV market and commercial space business. Further, NASA realized that risking human lives on space missions that did not require humans was unwise. In December 1986, President Reagan issued a directive stipulating that NASA would no longer launch satellites for private companies or foreign governments, unless they required a human presence in space or involved national security. This decision took the shuttle out of competition with ELVs for revenue-generating business. ${ }^{14}$ The idea of maintaining a "mixed fleet" of ELVs of various sizes and payload capabilities emerged in 1987 when NASA's Mixed Fleet Study was completed. GRC chaired the procurement development team for this study. Soon after this, in 1988, the concept of buying launch services instead of launch vehicles emerged. GRC was at the forefront of this transition.

Up until this time, NASA bought ELVs and was responsible for integrating them with payloads and launching them. For example, with Atlas/Centaur, GRC had separate contracts with General Dynamics for the Atlas and Centaur vehicles, Pratt \& Whitney for the RL10 engines, Rocketdyne for the Atlas MA-5 engines, Teledyne for the Centaur flight computer, and Honeywell for the Centaur guidance system. GRC was responsible for taking delivery of all of these hardware elements and integrating them together with General Dynamics into the final integrated vehicle. Pratt \& Whitney, Rocketdyne, Teledyne, and Honeywell were not subcontractors to General Dynamics. They were referred to as associate contractors. Their contracts were with GRC and they delivered their products to GRC. GRC then transferred these deliverables as GFE to General Dynamics, who performed the overall vehicle integration and tests. GRC was also responsible for integrating the payload and supporting KSC in launching the rockets from Air-Force-owned launch pads. GRC also owned the RL10 test stands at Pratt \& Whitney. NASA was responsible for the launch and the mission success. If there was a failure, NASA was responsible for the failure reviews. If a private company or another government agency wanted to launch their satellite on Atlas/Centaur, they 
had to approach GRC to procure and integrate the vehicle and manage the launch. This was the era of ELVs, from 1963 to 1989.

In 1987 the transition to launch services began. NASA would no longer buy vehicles, but would contract with commercial launch vehicle providers to buy their service to launch a particular payload into space. The launch vehicle provider became responsible for everything. In the case of Atlas/Centaur; Rocketdyne, Pratt \& Whitney, Honeywell, and Teledyne became subcontractors to General Dynamics. All of the NASA-owned property, equipment, and other assets was turned over to industry as part of a barter agreement in exchange for launching the Combined Release and Radiation Effects Satellite (CRRES) on AC-69. This barter agreement was an element (condition) of the Geosynchronous Operational Environmental Satellite (GOES) launch services contract negotiation. GOES became NASA's first commercial launch services contract and represented a milestone in the effort to commercialize the launch vehicle industry. ${ }^{15}$ AC-68, launched on September 25, 1989, carrying a FLTSATCOM satellite, was the last GRC-managed and -integrated mission of the "launch vehicle" era. GRC had managed 112 launches over a 26-year period. From this point forward, NASA would purchase launch services rather than launch vehicles. Staffing levels at GRC for launch services support dropped to 50 to 70 people. In July 1990, the first commercial launch of a NASA mission occurred with the launch of CRRES on AC-69. The new era of commercial space and launch services had begun. The barter agreement paved the way for the commercialization of Atlas/Centaur. It continues to this day with Centaur still flying as the upper stage of Atlas, now referred to as Atlas V. A very similar upper stage flies atop the Delta 4 launch vehicle. Today there are many other commercial launch providers, including Orbital Science, SpaceX, and United Launch Alliance (ULA, a Boeing/Lockheed Martin joint venture). Ariane continues to fly for Europe, as do ELVs from other foreign countries including Japan and Russia. In 2012 ULA celebrated the $200^{\text {th }}$ flight of Centaur. ULA is currently developing the next generation of Centaur. It is perhaps ironic and remarkable to note that while Centaur still flies today, the space shuttle (which almost caused the termination of Centaur and ELVs) does not.

During the 1990s, the first decade of launch services, GRC was responsible for procuring launch services for intermediate and large ELVs (i.e., Atlas/Centaur and Titan). Although these were launch services, GRC still maintained some responsibilities including independent verification and validation (IV\&V), leading-edge integration, independent analyses, mission design analyses, flight readiness assessments, supported spacecraft integration, and any NASA mission unique or peculiar requirements. For example, the Earth Observing System (EOS) AM-1 spacecraft had several mission-peculiar requirements that drove significant modifications to the baseline vehicle, including a new extended payload fairing, unique payload adapter and separation system, and a strengthened Centaur equipment module for the heavy and larger EOS payload. The EOS AM-1 spacecraft was originally designed to launch on the much more powerful Titan launch vehicle. When the change was made for budgetary reasons to launch on Atlas/Centaur, the spacecraft had to be downsized, but it still ended up being an unusually large and heavy payload for Atlas/Centaur. GRC performed all of the IV\&V analyses of the new designs, the structural test program, and the combined spacecraft/launch vehicle environment. EOS AM-1 was launched in December 1999 from a new Atlas launch complex (SLC-3E) at Vandenberg Air Force Base. This was the very first launch of an Atlas with a Centaur upper stage from Vandenberg. Other missions that GRC supported during this decade included CRRES (AC-69), Mars Observer (Titan III), GOES (AC-73, AC-77), SOHO (AC-121), and Cassini (Titan IV/Centaur).

In managing ELV launch services, GRC employed a variety of matrixed analysis capabilities to verify and validate mission planning and launch preparations. Typical activities included loads analyses, dynamics analyses, stability and control analyses, flight software IV\&V, guidance analyses, and trajectory/performance analyses. These independent analyses in critical or high-risk areas, using independently derived mathematical models, were then compared with the contractor's results. In 1998, a NASA "Zero Base Review" directed that all NASA ELV programs be transferred to KSC. This included GRC's responsibilities for intermediate- and large-class ELV launch services (i.e., Atlas/Centaur and Titan), as well as Goddard Space Flight Center's responsibility for small and medium class ELV launch services (i.e., Delta). This marked the end of GRC's long, 35-year association with Centaur and ELVs.

GRC led the creation of a new contractual means for the government to launch spacecraft. The transition from "launch vehicle" to "launch services," where NASA contracts with industry following $30+$ years of maturation of ELVs, enabled the government to streamline and pursue a cost-effective way to launch spacecraft by purchasing a service rather than the actual hardware. GRC pioneered the commercial launch services culture and was the first to implement the new national space policy on commercialization through innovative contracting provisions that have become the standard for NASA and DoD. GRC's pioneering launch services methods enabled NASA to retain technical insight while keeping costs low. 


\section{Thoughts on the Future}

It is hard to imagine today a program or project being managed and integrated like Centaur was. Times have changed, the environment is different, the industry has matured, and the roles of government and industry have evolved. A trusting, collaborative relationship between government and industry, like Centaur enjoyed, may be a relic of the past, but it is nevertheless something to strive for. The basic tenets of GRC's launch vehicle management philosophy are sound and relevant today: strong leadership; highly competent staff with deep technical knowledge, experience, and tools; well-defined roles and responsibilities, processes, and procedures; and a profound drive for mission success. The government's role needs to be more than just insight and oversight of the contractor. The "deep technical knowledge" of the staff needs to be allowed access to the contractor's design, development, production, and operations. This penetration need not be adversarial but rather in a spirit of collaboration, teamwork, and mutual trust for the common good of the mission - a "win-win" situation. This proposition will lead to much debate and many questions. Is this expensive, bureaucratic, unnecessary overkill? Shouldn't the government step back and stay out of industry's way? Isn't this "old school" and contrary to commercialization? Does the government (NASA) even have the personnel with deep technical knowledge and experience anymore? These are all valid questions that need to be thoughtfully considered by leaders, stakeholders, and customers.

What is the next Centaur? There are many launch vehicles and space transportation systems flying successfully today. SpaceX, with their Falcon launch vehicles and Dragon capsule, is one example. NASA's Space Launch System heavy lift booster and Orion Multi-Purpose Crew Vehicle are well into their development. Future in-space transportation systems likely will be higher performing than Centaur or any other chemical propulsion stage or spacecraft. Nuclear thermal propulsion with its high specific impulse and high thrust or solar electric propulsion (SEP) with its very high specific impulse (and low thrust) are being considered for future solar system missions and destinations, such as Mars and for the Asteroid Redirect Mission. The lessons learned from Centaur, and there are many, should be heeded as well as the techniques and philosophy employed by GRC.

GRC is leading the development of SEP and in-space SEP transfer stages/spacecraft development. As revolutionary as Centaur was in the 1960s in terms of high-energy performance and new capability development to enable new missions, SEP is this generation's Centaur. Hopefully some of the management and integration tenets for Centaur will be applied to SEP and other future space transportation systems.

\section{Conclusion}

The success and longevity of Centaur can be attributed to GRC's strong leadership, technical competency, and management philosophy for launch vehicle integration. Although this paper is about GRC's role, one should not undervalue the role of General Dynamics and the other industry partners that equally share in the success of Centaur. It was a true team effort and collaboration. Although GRC managed and led the launch vehicle integration, as well as the development of the Centaur upper stage, the work was largely done by a team of industry partners under contract to GRC. However, GRC did far more than just manage the contracts and provide oversight and insight. The GRC launch vehicle team worked side-by-side with their industry counterparts on almost all aspects of Centaur development and integration, including the major configuration changes described in this paper. The GRC team had longevity, continuity, and the corporate knowledge of launch vehicles and Centaur. GRC's knowledge of every detail of Centaur, down to individual components such as valves and fasteners, sometimes exceeded that of industry. Both GRC and industry personnel had immense pride in Centaur and their contributions to its success. Each launch culminated a multiyear "intimate relationship" life cycle with that particular vehicle. Each vehicle had its own unique history, pedigree, and problems to overcome that the team lived and breathed every day. It was exhilarating when the launch was successful and devastating when the launch ended in failure. Centaur continues to be the workhorse, high-energy upper stage for the nation. Go Atlas. Go Centaur.

\section{Acknowledgments}

Scott R. Graham thanks Craig Williams, Edward Muckley, Donald Palac, Bryan Smith, and John "Joe" Nieberding for their help and contributions to this paper. 


\section{References}

${ }^{1}$ NASA Lewis Research Center, "Report of the Atlas/Centaur Review Board," chaired by Dr. Bruce T. Lundin, NASA Glenn History Collection, Centaur Collection, NASA Glenn Research Center, Cleveland, OH, 1981, p. 5 (unpublished 1981 internal NASA report to NASA Headquarters).

2 NASA Lewis Research Center, "Launch Vehicles Division Presentation to the Space Directorate," NASA Glenn Research Center Internal Presentation Charts, Cleveland, OH, 1980 (unpublished).

${ }^{3}$ NASA Lewis Research Center, "Report of the Atlas/Centaur Review Board," chaired by Dr. Bruce T. Lundin, NASA Glenn History Collection, Centaur Collection, NASA Glenn Research Center, Cleveland, OH, 1981, p. 6 (unpublished 1981 internal NASA report to NASA Headquarters).

${ }^{4}$ NASA Lewis Research Center, "Report of the Atlas/Centaur Review Board," chaired by Dr. Bruce T. Lundin, NASA Glenn History Collection, Centaur Collection, NASA Glenn Research Center, Cleveland, OH, 1981, p. 7 (unpublished 1981 internal NASA report to NASA Headquarters).

${ }^{5}$ Dawson, Virginia P., and Bowles, Mark D., "Taming Liquid Hydrogen: The Centaur Upper Stage Rocket 1958-2002," NASA SP-2004-4230, 2004, pp. 71-75.

${ }^{6}$ NASA Lewis Research Center, "NASA Center Roles in Management of Intermediate and Large Class ELVs," NASA Lewis Research Center Internal Presentation Charts, Cleveland, OH, 1988 (unpublished).

${ }^{7}$ Dawson, Virginia P., and Bowles, Mark D., "Taming Liquid Hydrogen: The Centaur Upper Stage Rocket 1958-2002,” NASA SP-2004-4230, 2004.

${ }^{8}$ Dawson, Virginia P., and Bowles, Mark D., "Taming Liquid Hydrogen: The Centaur Upper Stage Rocket 1958-2002," NASA SP-2004-4230, 2004, p. 143

${ }^{9}$ Dawson, Virginia P., and Bowles, Mark D., "Taming Liquid Hydrogen: The Centaur Upper Stage Rocket 1958-2002," NASA SP-2004-4230, 2004, p. 144.

${ }^{10}$ NASA Lewis Research Center, "Report of the Atlas/Centaur Review Board," chaired by Dr. Bruce T. Lundin, NASA Glenn History Collection, Centaur Collection, NASA Glenn Research Center, Cleveland, OH, 1981, p. 3 (unpublished 1981 internal NASA report to NASA Headquarters).

${ }^{11}$ NASA Lewis Research Center, "Report of the Atlas/Centaur Review Board," chaired by Dr. Bruce T. Lundin, NASA Glenn History Collection, Centaur Collection, NASA Glenn Research Center, Cleveland, OH, 1981, p. 2 (unpublished 1981 internal NASA report to NASA Headquarters).

${ }^{12}$ Dawson, Virginia P., and Bowles, Mark D., "Taming Liquid Hydrogen: The Centaur Upper Stage Rocket 1958-2002," NASA SP-2004-4230, 2004, p. 167.

${ }^{13}$ Dawson, Virginia P., and Bowles, Mark D., "Taming Liquid Hydrogen: The Centaur Upper Stage Rocket 1958-2002," NASA SP-2004-4230, 2004, p. 196.

${ }^{14}$ Dawson, Virginia P., and Bowles, Mark D., "Taming Liquid Hydrogen: The Centaur Upper Stage Rocket 1958-2002,” NASA SP-2004-4230, 2004, p. 233.

${ }^{15}$ Dawson, Virginia P., and Bowles, Mark D., "Taming Liquid Hydrogen: The Centaur Upper Stage Rocket 1958-2002," NASA SP-2004-4230, 2004, p. 237. 